The running title: Psychopathic traits in treatment-seeking girls

\title{
Self-rated psychopathic traits in a sample of treatment-seeking adolescent girls with internalizing and externalizing disorders: comparisons to girls in the community
}

Svetlana Oshukova, $\mathrm{MD}^{1}$; Riittakerttu Kaltiala-Heino, $\mathrm{PhD}^{2,3,4}$; Jouko Miettunen, $\mathrm{PhD}^{5,6,7}$; Riikka Marttila, MSc ${ }^{5,6,7}$; Eeva T. Aronen, $\mathrm{PhD}^{8}$; Mauri Marttunen, $\mathrm{PhD}^{9,10}$; Matti Kaivosoja, $\mathrm{PhD}^{11,12}$; and Nina Lindberg, $\mathrm{PhD}^{13^{*}}$

${ }^{1}$ University of Helsinki and Helsinki University Hospital, Psychiatry, Helsinki, Finland

${ }^{2}$ Tampere University, School of Medicine, Tampere, Finland

${ }^{3}$ Tampere University Hospital, Department of Adolescent Psychiatry, Tampere, Finland

${ }^{4}$ Vanha Vaasa Hospital, Vaasa, Finland

${ }^{5}$ Research Unit of Clinical Neuroscience, Department of Psychiatry, University of Oulu and Oulu University Hospital, Oulu, Finland

${ }^{6}$ Medical Research Center Oulu, Oulu University Hospital and University of Oulu, Oulu, Finland

${ }^{7}$ Center for Life Course Health Research, University of Oulu, Oulu, Finland

${ }^{8}$ University of Helsinki and Helsinki University Hospital, Children's Hospital, Child Psychiatry, Helsinki, Finland

${ }^{9}$ University of Helsinki and Helsinki University Hospital, Adolescent Psychiatry, Helsinki, Finland

${ }^{10}$ National Institute for Health and Welfare, Mental Health Unit, Helsinki, Finland 
${ }^{11}$ Turku University, Department of Child Psychiatry, Turku, Finland

${ }^{12}$ Hospital Districts of Central Ostrobothnia, Kokkola, Finland

${ }^{13}$ University of Helsinki and Helsinki University Hospital, Forensic Psychiatry, Helsinki, Finland

*Corresponding author:

Svetlana Oshukova

Helsinki University Hospital

P.O. Box 282

00029 HUS

Helsinki

Finland

tel: +358503775191

e-mail: svetlana.oshukova@hus.fi 


\begin{abstract}
Background: Psychopathy research has thus far focused mostly on child, male and delinquent samples, but the results are most likely non-generalizable to adolescent girls with mental health disorders.
\end{abstract}

Aim: The present study aimed to compare self-rated psychopathic traits between female psychiatric outpatients and girls in the community, and to investigate how psychopathic traits relate to psychiatric disorders.

Method: The outpatient sample comprised 163 girls aged 15- to 17-years recruited from municipal mental health services. Psychiatric diagnoses were assessed based on the ICD-10 classification. The community sample comprised 355 girls from secondary, vocational and high schools. The Youth Psychopathic trait Inventory (YPI) served as a self-assessment tool.

Results: Treatment-seeking girls exhibit a more impulsive and irresponsible life-style than do girls in the community. Girls with externalizing psychopathology, unlike those with an internalizing disorder, exhibit more deficient affective experience than do girls in the community. Psychopathic traits associate with having a psychiatric disorder, a depressive disorder, ADHD and a conduct disorder.

Conclusions: The psychiatric examination of treatment-seeking adolescent girls would likely benefit from screening for psychopathy and its underlying components.

Keywords: externalizing disorders, girls, internalizing disorders, out-patients, psychopathic traits

\title{
Introduction
}


Adolescence is a transitional stage from childhood to adulthood during which the individual undergoes many physiological, psychological, cognitive, and social changes. Internalizing symptoms, including depressive, anxiety, somatic and stress-related ones, begin to rise, especially among girls (1). Boys exhibit higher prevalence rates of externalizing symptoms, including hyperactivity, disruptive, rule-breaking and aggressive behaviors than do girls, but this gender gap narrows in adolescence (2). As a result, adolescence is a risk period for the emergence of both internalizing and externalizing mental health disorders in girls (3). Approximately one adolescent in five suffers from a psychiatric disorder (1), and mood, anxiety and eating disorders are all female dominated phenomena (3). In Finland, about 3\% of the adolescent population is referred to adolescent psychiatric secondary care, and the majority of clients seeking help are girls (4).

Psychopathy is a constellation of interpersonal (dishonest charm, grandiosity, lying, and manipulative behavior), affective (remorselessness, unemotionality, and callousness), and behavioral (thrill-seeking, impulsivity, and irresponsibility) character traits (5). Psychopathic traits have been regarded as relatively stable over time, from childhood through adolescence to adulthood, but, on the other hand, traits can change across favorable development and treatment (6). Psychopathic traits can be seen on a dimensional continuum, where psychopathy is a malicious version of the extremes of normal personality traits (7). Thus, these traits do not exist only in adolescents identified because of their antisocial or criminal behavior. A majority of studies have identified lower psychopathic traits in females than in males (8), and their etiology seems to differ between genders $(9,10)$. Findings on sex differences in genetic and environmental influences underlying the psychopathic traits vary. In some studies no gender differences in the genetic and environmental etiological factors magnitude were found (9, Tuvblad et al 2014)), some researchers found differences in etiological connections between specific psychopathic traits and psychopathology (Blonigen 2005), while some evidence supports a lower heritability of 
psychopathic traits (11-13) as well as a greater role of family-related risk factors (14) in girls. Evidence also indicates different expression of psychopathy in girls and boys where, among girls, the interpersonal and affective features more clearly capture psychopathy than do the behavioral ones (15).

Psychopathic traits are related to mental health disorders (16), and treatment-seeking juveniles show higher self-assessed levels of psychopathic traits than do community youth (17). Externalizing disorders associate strongly with elevated traits of psychopathy, and some research has even suggested that the same biological and environmental factors play a role in the etiology of conduct disorder and psychopathy (16). The relation between ADHD and elevated traits of psychopathy is mostly mediated by conduct disorder (16), although ADHD seems to have a small independent contribution to elevated psychopathy scores as well (18). The relationship between internalizing psychopathology and psychopathic traits is still substantially more obscure. Internalizing disorders are often assumed to vary inversely with psychopathic traits, but the magnitude and direction of the relations between psychopathic traits, anxiety, and depression symptomatology have shown striking variance $(16,19)$. Unfortunately, to date, most studies focusing on the relationship between psychopathic traits and other forms of psychopathology have been performed in samples that include both children and adolescents, only boys, or among delinquents, who are most likely at the high end of the distribution of psychopathic traits; this relationship in girls remains largely unexamined. In a Swedish sample of mid-adolescent female outpatients with substance use disorders, the psychopathy scores correlated positively with conduct disorder symptoms, but not with ADHD, eating disorder, depressive, or anxiety symptoms (20). According to an inpatient study by Murrie and Cornell (21), girls with high traits of psychopathy showed significantly lower levels of self-rated anxiety symptoms than did those with low levels of psychopathy, but no significant difference was seen in depressive symptoms or eating dysfunction. 
Taken together: psychopathy research has thus far focused mostly on child, male and delinquent samples, but the results are most likely non-generalizable to adolescent girls with mental health disorders. The issue is important, since girls represent the majority of clients in adolescent psychiatry secondary care, and psychopathic traits are known to affect both the prognosis $(22,23)$ and chosen treatment interventions $(24,25)$. The present study aimed to compare self-rated psychopathic traits between treatment-seeking girls and girls in the community, and to investigate how psychopathic traits relate to psychiatric disorders. We hypothesized that girls with mental health disorders would show significantly higher levels of psychopathic traits than girls in the community, and that psychopathic traits would relate significantly with externalizing disorders, but not with internalizing disorders.

\section{Methods}

\section{Outpatients}

We collected the data from one hospital located in Southern Finland, the population of which comprises approximately 180,000 inhabitants. The hospital area has a total of three municipal psychiatric outpatient clinics for the adolescent population aged from 13 to 17 years. This study population comprised all 15-to 17-year- old girls from these clinics during one year. The total number of female outpatients was 389 of whom 163 (41.9\%) agreed to participate in the study. The mean age of the final sample was 16.0 years (SD 0.86). The diagnoses of the outpatients were based on careful anamneses and clinical assessment by the multidisciplinary team of professionals specialized in adolescent psychiatry. No one was diagnosed with an intellectual disability, so all the patients were considered to be of normal intelligence. 


\section{Community sample}

The sample comprised a classroom survey among 15 - to 17 - year-old girls in secondary $(n=5)$, vocational $(n=1)$ and high $(n=2)$ schools of one Finnish western coastal city with approximately 47,000 inhabitants. Of 415 girls, $52(12.5 \%)$ did not participate in the study because they either did not attend school on the study day or refused to participate. Of the remaining students, 5 did not complete the self-assessment and 3 did not inform their gender in the filled questionnaire and were omitted. Thus, the sample comprised 355 community girls. The mean age of the girls was 15.7 (SD $0.83)$.

\section{Procedure and ethical aspects}

Psychiatric nurses working as research assistants contacted all outpatients. The outpatients received both oral and written information about the study and were assured that participation was voluntary. Those, who agreed to participate in the study, gave their written consent and completed the selfassessment during their ordinary visits to outpatient clinics. We collected each participant's name and personal identity number as background variables.

The community sample completed the self-assessment during their ordinary school lessons. They also received information about the study both verbally and in a cover letter. They were assured of the confidentiality and anonymity of the data and of the voluntary nature of participation. By returning the completed questionnaire, the participants confirmed their consent. The participants' age and gender served as background variables.

After completing the self-assessment, each participant placed it into an envelope, sealed the envelope, and returned the sealed envelope to the research assistant (outpatients) or to the teacher (pupils). The adolescents were informed that they had the possibility to contact the researchers (who 
offered their e-mail addresses and telephone numbers) if the content of the self-assessment raised questions or ideas, that they wanted to share with the researchers. The Finnish Medical Research Act allows individuals aged 15- to 17 years to participate in medical research projects without the permission of their guardians. The guardians must be, however, informed about the study. In line with this principle, guardians of the adolescents received a letter informing them of the study, and inviting them to familiarize themselves with the self-assessment. They also had a possibility to contact the researchers. The Ethics Committee of the Helsinki and Uusimaa Hospital District evaluated the study plan, and the administration of the Helsinki and Uusimaa Hospital District as well as the administration of the schools granted permission to conduct the study. The study was performed in accordance with the Declaration of Helsinki.

\section{Assessment of psychopathic traits}

Psychopathic traits were assessed using the Youth Psychopathic traits Inventory (YPI) (26), which is a 50-item self-report instrument for adolescents to measure the three personality dimensions of psychopathy: an arrogant and deceitful interpersonal style (the Interpersonal dimension), a deficient affective experience (the Affective dimension), and an impulsive and irresponsible behavioral style (the Behavioral dimension). The Interpersonal dimension consists of four subscales: Dishonest Charm, Grandiosity, Lying, and Manipulation; the Affective dimension of three subscales: Callousness, Unemotionality, and Remorselessness; and the Behavioral dimension of three subscales: Impulsiveness, Irresponsibility, and Thrill seeking. Items are scored on a four-point Likert-type scale $(1=$ does not apply at all, $4=$ applies very well); thus, the total score of the scale can range from 50 to 200, with a higher score representing a higher level of the trait. The measurement has no official cut-off score. The original YPI showed internal consistencies ranging from marginal (subscale Callousness: Cronbach's alpha =0.66; Unemotionality: 0.67) to acceptable 
and good (other subscales: 0.71-0.82) (26). Later, and with versions in various languages, the YPI has shown moderate to good psychometric properties (27). In this study, we used the authorized Finnish version of the YPI (28). The English version of the YPI served as a basis and the translation was performed according to the recommendations of the developers (http://www.oru.se/jps/downloadYPI/) involving an iterative process of translation and independent back translation, followed by a discussion to resolve minor differences.

\section{Psychiatric disorders}

Psychiatric diagnoses based on the ICD-10 classification (29) were established by a multidisciplinary team including a psychiatrist, a psychologist, a social worker, a psychiatric nurse, and an occupational therapist, all specialized in adolescent psychiatry. In addition, prior medical records and information gathered from the family, school and child welfare served in the diagnostic procedure. Because psychiatric symptomatology typically changes (usually for the better) during treatment, diagnoses were those assessed closest to the date when the person completed the YPI. Because outpatient clinics routinely carry out intermediate evaluations every three months, the maximum duration between the diagnostic assessments and completion of the YPI was three months. In cases of comorbidity, the priority of assessed diagnoses was discussed with the treating psychiatrists, and the principal diagnoses were used in the analyses.

\section{Statistical Analyses}

In line with previous YPI studies $(26,28,31,32)$, we calculated and used averaged scores in the analyses. The original data was skewed, and we performed logarithm transformation. We compared the groups with the one-way ANOVA. The post-hoc testing was performed with the Tukey method. 
The associations between the psychopathy scores and psychiatric disorders were analyzed with logistic regression analysis. The YPI scores of the community youth served as a baseline. As the minimum of the YPI mean scores was 1 and the maximum 4, a three-point Likert-type scale was developed: 1 (including mean values <2), 2 (including mean values 2- 3), and 3 (including mean values $>3$ ). Thus, the logistic regression analysis revealed the risk to have a psychiatric disorder (any psychiatric disorder, a depressive disorder, an anxiety disorder, an eating disorder, ADHD, a conduct disorder, an internalizing disorder, and an externalizing disorder) as a consequence of one point increase in psychopathic traits on the Likert-type scale. The logistic regression analysis was performed with age-adjusted values. In order to check the results, we performed the same analysis using the continuous scores of the YPI. Findings were considered significant when the two-tailed $p$ $<0.05$. The odds ratios (ORs) with $95 \%$ confidence intervals (CIs) are reported. The statistical analyses were performed with IBM SPSS Statistics version 22.

\section{Results}

Internal consistency coefficients for the YP

The Cronbach's alphas as measures of internal consistency were calculated. In the outpatient sample, the alpha value for the total score was 0.87 ; for the Interpersonal dimension score 0.84 ; for the Affective dimension score 0.77 ; and for the Behavioral dimension score 0.75 . Respectively, in the community sample, the alpha values were $0.87,0.85,0.75$ and 0.78 .

\section{Psychiatric disorders in outpatient girls}

The distribution of diagnostic groups according to the principal diagnoses appears in Table 1. In line with a recent study by Rytilä-Manninen et al. (30), depressive (F32-33; n= 63), anxiety (F4043; $n=53)$ and eating disorders ( $F 50 ; n=13)$ were combined into a group of internalizing disorders $(n=129)$ and, respectively, ADHD (F90.0; $n=6)$ and conduct disorders (F91-92; $n=13)$ into a group of externalizing disorders $(n=19)$. 
Comparisons between outpatients with internalizing and externalizing disorders and girls in the community

Girls with an internalizing disorder exhibited significantly lower total and dimensional scores of the YPI than girls with externalizing psychopathology (Table 2). Girls with an externalizing disorder showed significantly higher total as well as both the Affective and Interpersonal dimension scores than did girls in the community. Both patient groups scored significantly higher on the Behavioral dimension of the YPI than did girls in the community.

Odds ratios for having a psychiatric disorder

With regard to total psychopathy scores, the ORs (Table 3) indicated a significant risk for a psychiatric disorder, a depressive disorder, ADHD, a conduct disorder as well as for an externalizing disorder as a consequence of a one-point increase on the Likert-type scale. With regard to the Interpersonal dimension, a significant risk was found for an externalizing disorder, and, respectively, with regard to the Affective dimension, for ADHD, a conduct disorder, and an externalizing disorder. Finally, with regard to the Behavioral dimension, the ORs indicated a significant risk for a psychiatric disorder, a depressive disorder, ADHD, a conduct disorder, an internalizing disorder, and an externalizing disorder. These associations remained significant when the logistic regression analysis was performed with continuous scores (this additional file can be asked from the corresponding author).

\section{Discussion}

To our knowledge, this is one of few studies investigating psychopathic traits in treatment-seeking adolescent girls with mental health disorders. As expected, girls with an externalizing disorder exhibited significantly higher traits of psychopathy than did those suffering from an internalizing 
disorder. The data only partially supported our hypothesis that patients would show higher levels of psychopathic traits than would girls in the community. This was true in girls with externalizing psychopathology, but when girls with an internalizing disorder were compared to girls in the community, no significant difference emerged. With regard to underlying dimensional traits, girls with an externalizing disorder showed significantly more deficient affective experience than did other girls. Both patient groups exhibited significantly more impulsive and irresponsible life style (behavioral component of psychopathy) than girls in the community. Researchers have increasingly emphasized the affective deficit as the "core" of the psychopathy syndrome (19), providing greater information about current and future impairment as well as aiding more in treatment planning (33 34). Contrary to this, the role of impulsivity as part of the psychopathy construct has been predisposed to re-evaluation. Originally, impulsivity was considered as a prominent feature of the syndrome $(35,36)$, and assessment tools delivered from the Hare Psychopathy Checklist (5), the gold standard in assessing psychopathic traits, include impulsivity as one of the psychopathic features. A recent review by Poythress and Hall (37) questioned, however, the value of impulsivity as a marker for the assessment of psychopathy, and some researchers $(38,39)$ have regarded the whole behavioral component more as a consequence of the psychopathy syndrome. In any case, it is noteworthy that a substantial trait difference on the Behavioral dimension was observed between girls with internalizing psychopathology and those in the community even though the groups did not significantly differ from each other either on the total psychopathy score or on the Affective or Interpersonal dimension scores.

Elevated traits of psychopathy relate to general psychopathology (19), and, consequently, girls' psychopathic traits associated significantly with having an ICD-10- based psychiatric disorder. In line with a Swedish study of female substance abusers (20), psychopathic traits related significantly with having a conduct disorder. Contrary to it, we found a significant association also between psychopathic traits and ADHD. With regard to underlying dimensions, both disorders associated 
significantly with deficient affective experience as well as with an impulsive and irresponsible lifestyle. All in all, the relationship between psychopathic traits and externalizing psychopathology in treatment-seeking adolescent girls resembled that reported in numerous previous child, male and delinquent samples (16). Unlike the Swedish study (20), we found a significant association between psychopathic traits and having a depressive disorder. On the dimensional level, it was the behavioral component, which associated significantly with the disorder. In adolescence, unlike in adulthood, a major depressive disorder is often characterized by a tendency towards irritable mood, which, for example, the DSM classification (34) defines as "persistent anger, a tendency to respond to events with angry outbursts or blaming others, or an exaggerated sense of frustration over minor matters". Thus, our finding may reflect a genuine personality trait, but it may mirror the depressive symptomatology itself, mimicking psychopathy. If the latter were the case, one might expect the psychopathy score to diminish with recovery of depression. On the other hand, depression is highly related to suicidality (40), and, in girls, impulsive-irresponsible traits of psychopathy contribute to both suicide attempts and other self-injurious behavior (17). Callous-unemotional traits, in contrast, seem to confer protection from suicide attempts (17). In this study, no significant association was observed between the Affective dimension of psychopathy and having a depressive disorder. Like the Swedish outpatient study (20) and in line with our hypothesis, we were not able to find significant associations between psychopathic traits and having an anxiety or eating disorder.

\section{Limitations}

Even though the participation rate of community girls was good, that of outpatients remained relatively small, as only approximately $42 \%$ of the outpatients agreed to provide their consent. Considering that the study focused on psychopathic traits and reviewed the patients' files, it is not surprising that the recruitment was challenging, especially among those with externalizing disorders. The diagnoses were based not on a structured clinical interview instrument (e.g., the K- 
SADS), but, instead, on the multidisciplinary team work of professionals specialized in adolescent psychiatry. In this regard, the basic diagnostic procedures in Finland are reliable $(41,42)$. The patients were estimated to be of normal intelligence, and the professionals made no diagnoses of intellectual disability. In the hospital area, where the study took place, adolescent patients with neuropsychiatric, substance use and serious eating disorders are referred to special tertiary units rather than to local adolescent psychiatric outpatient clinics. Further, in Finland, most adolescents with conduct disorders receive treatment under child welfare services, not under the specialty of adolescent psychiatry. In the present study, the distribution of diagnostic groups clearly reflects this general division of labor. The pupils and the outpatients came from different towns. Finland is, however, a relatively small and both culturally and financially homogenous country indicating that the differences between the samples were modest. One must also bear in mind that our crosssectional study addressed only concurrent comorbidity. Studying how psychopathic traits relate to prognosis will require further research.

\section{Conclusions}

Treatment-seeking adolescent girls with mental health disorders show a more impulsive and irresponsible life style than do girls in the community. With regard to deficient affective experience, only girls with externalizing psychopathology differ significantly from girls in the community. The logistic regression analysis revealed significant associations between psychopathic traits and having a psychiatric disorder, a depressive disorder, ADHD, and a conduct disorder. Screening psychopathy and its underlying components as part of a psychiatric examination of treatmentseeking girls seems to be relevant. 


\section{Acknowledgements:}

This study received funding from the Helsinki and Uusimaa Hospital District and Academy of Finland (\#268336). We thank the authorities of the Department of Psychiatry, Helsinki University Hospital and Kellokoski Hospital. Disclosure of interest: The authors report no conflicts of interest. The authors alone are responsible for the content and writing of the paper

\section{References}

1. Costello EJ, Copeland W, Angold A. Trends in psychopathology across the adolescent years: what changes when children become adolescents, and when adolescents become adults? J Child Psychol Psychiatry 2011;52:1015-25.

2. Hicks BM, Blonigen DM, Kramer MD, Krueger RF, Patrick CJ, Iacono WG. et al. Gender differences and developmental change in externalizing disorders from late adolescence to early adulthood: A longitudinal twin study. J Abnorm Psychol 2007;116:433- 47.

3. Kessler RC, Avenevoli S, Costello EJ, Georgiades K, Green JG, Gruber MJ. et al. Prevalence, persistence, and sociodemographic correlates of DSM-IV disorders in the National Comorbidity Survey Replication Adolescent Supplement. Arch Gen Psychiatry 2012;69:372-80.

4. Pylkkänen K. Quality guidelines for Adolescent Psychiatry. Psychiatr Fennica 2013;44:89-94.

5. Hare RD. The Hare Psychopathy Checklist- Revised, 2nd edition. Toronto: Multi-Health Systems; 2003.

6. Frick PJ, Ray JV, Thornton LC, Kahn RE. A developmental psychopathology approach to understanding callous-unemotional traits in children and adolescents with serious conduct problems. J Child Psychol Psychiatry 2014;55:532-48. 
7. Miller JD, Lynam DR. Psychopathy and personality: advances and debates. J Pers. 2015;83:585-

9.

8. Weizmann-Henelius G, Putkonen H, Grönroos M, Lindberg N, Eronen M, Häkkänen-Nyholm H. Examination of psychopathy in female homicide offenders- confirmatory factor analysis of the PCL-R. Int J Law Psychiatry 2010;33:177-83.

9. Hicks BM, Carson MD, Blonigen DM, Patrick CJ, Iacono WG, MGue M. Psychopathic personality traits and environmental context: differential correlates, gender differences and genetic mediation. Personal Disord 2012;3:209-27.

10. Rubio JS, Krieger MA, Finney EJ, Coker KL. A review of the relationship between sociocultural factors and juvenile psychopathy. Aggress Violent Beh 2014;19:23-31.

Tuvblad C, Bezdijan S, Raine A, Bakr LA. The heritability of psychopathic personality in 14- to 15year-old twins: a multirater, multimeasure approach. Psychol Assess 2014;26:704-16

Blonigen DM, Hicks BM, Krueger RF, Patrick JC, Iacono WG. Psychopathic personality traits: heritability and genetic overlap with internalizing and externalizing psychopathology. Psychol Med 2005;35:637-48.

11. Viding E, Frick PJ, Plomin R. Aetiology of the relationship between callous-unemotional traits and conduct problems in childhood. Br J Psychiatry Suppl. 2007;49:33-8.

12. Fontaine NM, Rijsdijk FV, McCrory EJ, Viding, E. Etiology of different developmental trajectories of callous-unemotional traits. J Am Acad Child Adolesc Psychiatry 2010;49:656-64. 
13. Bezdjian S, Raine A, Baker LA, Lynam DR. Psychopathic personality in children: genetic and environmental contributions. Psychol Med 2011;41:589-600.

14. Kricher MK, Sevecke K. Early traumatization and psychopathy in female and male juvenile offenders. Int J Law Psychiatry 2008;31:253-62.

15. Schrum CL, Salekin RT. Psychopathy in adolescent female offenders: an item response theory analysis of the psychopathy checklist: youth version. Behav Sci Law 2006;24:39-63.

16. Sevecke K, Kosson DS. Relationships of child and adolescent psychopathy to other forms of psychopathology. In: Salekin RT, Lynam DR, editors. Handbook of Child \& Adolescent Psychopathy. New York: The Guilford Press; 2010. p. 284-314.

17. Javdani S, Sadeh N, Verona, E. Suicidality as a Function of Impulsivity, Callous/Unemotional Traits, and Depressive Symptoms in Youth. J Abnorm Psychol. 2011;120:400-13.

18. Abramowitz CS, Kosson DS, Seidenberg M. The relationship between childhood attention deficit hyperactivity disorder and conduct problems and adult psychopathy in male inmates. Pers Individ Dif 2004;36:1031-47.

19. Willemsen J, Verhaeghe P. Psychopathy and internalizing psychopathology. Int J Law Psychiatry. 2012;35:269-75.

20. Hemphälä M, Tengström A. Associations between psychopathic traits and mental disorders among adolescents with substance use problems. Br J Clin Psychol. 2010;49:109-22.

21. Murrie DC, Cornell DG. The Millon adolescent clinical inventory and psychopathy. J Pers Assess. 2000;75:110-25. 
22. O'Neill ML, Lidz V, Heilbrun K. Adolescents with psychopathic characteristics in a substance abusing cohort: treatment process and outcomes. Law Hum Behav 2003;27:299-313.

23. Salekin RT. Treatment of Child and Adolescent Psychopathy: focusing on change. In: Salekin RT, Lynam DR, editors. Handbook of Child \& Adolescent Psychopathy. New York: The Guilford Press; 2010. p. 343-73.

24. Frick PJ, Ray JV, Thornton LC, Kahn RE. Can callous-unemotional traits enhance the understanding, diagnosis, and the treatment of serious conduct problems in children and adolescents? A comprehensive review. Psychol Bull 2014;140,1-57.

25. Hawes DJ, Price MJ, Dadds MR. Callous-Unemotional Traits and the Treatment of Conduct Problems in Childhood and Adolescence: A Comprehensive Review. J Child Psychol Psychiatry $2014 ; 17: 248-67$.

26. Andershed H, Kerr M, Stattin H, Levander S. Psychopathic traits in non-referred youths: Initial test of a new assessment tool. In E. Blaauw \& L. Sheridan (Eds.), Psychopaths: Current international perspectives, Den Haag, The Netherlands: Elsevier; 2002, p 131-158.

27. Kotler JS, McMahon RJ. Assessment of Child and Adolescent Psychiatry. In: Salekin RT, Lynam DR, editors. Handbook of Child \& Adolescent Psychopathy. New York: The Guilford Press; 2010. p.79-109.

28. Oshukova S, Kaltiala-Heino R, Miettunen J, Marttila R, Tani P, Aronen ET et al. Self-reported psychopathic traits among non-referred Finnish adolescents: psychometric properties of the Youth Psychopathic traits Inventory and the Antisocial Process Screening Device. Child Adolesc Psychiatry Ment Health 2015;6:15. 
29. World Health Organization. The ICD 10 Classification of Mental and Behavioural Disorders. WHO; 1992.

30. Rytilä-Manninen M, Lindberg N, Haravuori H, Kettunen K, Marttunen M, Joukamaa M. et al. Adverse childhood experiences as risk factors for serious mental disorders and inpatient hospitalization among adolescents. Child Abuse Negl 2014;38:2021-32.

31. Hillege S, Das J, de Ruiter C. The Youth Psychopathic traits Inventory: psychometric properties and its relation to substance use and interpersonal style in a Dutch sample of non-referred adolescents. J Adolesc. 2010;33:83-91.

32. Skeem JL, Cauffman E. Views of the downward extension: comparing the youth version of the psychopathy checklist with the youth psychopathic traits inventory. Behav Sci Law. 2003;21:73770.

33. Colins OF, Andershed H. The DSM-5 with limited prosocial emotions specifier for conduct disorder among detained girls. Law Hum Behav. 2015;39:198-207.

34. American Psychiatric Association. Diagnostic and Statistical Manual of Mental Disorders. 5th ed. Washington DC: American Psychiatric Press, 2013.

35. Cleckley H. The mask of sanity ( ${ }^{\text {th }}$ ed.). St. Louis: Mosby, 1964.

36. Hare RD. Without conscience: the disturbing world of the psychopaths among us. New York: Guilford, 1993.

37. Poytress NG, Hall JR. Psychopathy and impulsivity reconsidered. Aggress Violent Behav. 2011;16:120-34. 
38. Cooke DJ, Michie C, Hart SD, Clark DA. Reconstructing psychopathy: clarifying the significance of antisocial and socially deviant behaviour in the diagnosis of psychopathic personality disorder. J Pers Disord. 2004;18:337-57.

39. Skeem JL, Cooke DJ. Is criminal behavior a central component of psychopathy? Conceptual directions for resolving the debate. Psychol Assess. 2010;22: 433-45.

40. Marttunen MJ, Aro HM, Henriksson MM, Lönnqvist JK. Mental disorders in adolescent suicide. DSM-III-R axes I and II diagnoses in suicides among 13- to 19-year-olds in Finland. Arch Gen Psychiatry. 1991;48:834-9.

41. Isohanni M, Mäkikyrö T, Moring J, Räsänen P, Hakko H, Partanen U. et al. A comparison of clinical and research DSM-III-R diagnoses of schizophrenia in a Finnish national birth cohort. Clinical and research diagnoses of schizophrenia. Soc Psychiatry Psychiatr Epidemiol. $1997 ; 32,303-8$.

42. Pihlajamaa J, Suvisaari J, Henriksson M, Heilä H, Karjalainen E, Koskela J. et al. The validity of schizophrenia diagnosis in the Finnish Hospital Discharge Register: findings from a 10-year birth cohort sample. Nord J Psychiatry 2008;62,198-203. 
Table 1. The distribution of the ICD-10 based principal psychiatric disorders among female psychiatric out-patients $(n=163)$.

\begin{tabular}{ll}
\hline ICD-10 & $\mathrm{n}(\%)$
\end{tabular}

F20-29 Schizophrenia, schizotypal and delusional disorders $5(3.1)$

F30-39 Mood disorders

F32-33 Depressive disorders

F40-48 Neurotic, stress-related and somatoform disorders

F40-43 Anxiety disorders

F50-59 Behavioral syndromes associated with physiological $13(8.0)$ disturbances and physical factors

F50 Eating disorders $13(8.0)$

F60-69 Disorders of adult personality and behavior

F80-89 Pervasive and specific developmental disorders

F90-98 Behavioral and emotional disorders

F90 Hyperkinetic disorders

F90.0 ADHD $6(3.6)$

F91 Conduct disorders

F92 Mixed disorders of conduct and emotions $11(6.7)$ F99 Unspecified mental disorder $1(0.6)$ 
Table 2. Comparisons between 15 - to 17 -year-old female psychiatric out-patients with internalizing $(n=129)$ and externalizing disorders $(n=19)$ and community girls $(n=355)$ on the Youth Psychopathic traits Inventory (YPI) scores. The groups were compared with the one-way ANOVA. The post-hoc testing was performed with Tukey method.

\begin{tabular}{|c|c|c|c|c|c|c|c|c|c|c|}
\hline & \multirow{2}{*}{$\begin{array}{c}\text { INT } \\
\text { Mean(SD) }\end{array}$} & \multirow{2}{*}{$\begin{array}{c}\text { EXT } \\
\text { Mean(SD) }\end{array}$} & \multirow{2}{*}{$\begin{array}{c}\text { COM } \\
\text { Mean(SD) }\end{array}$} & \multicolumn{4}{|c|}{ Statistics } & \multicolumn{3}{|c|}{ Post-hoc testing } \\
\hline & & & & Fadj & $\mathrm{p}$ & $\mathrm{F}$ & $\mathrm{p}$ & & $\mathrm{q}$ & $\mathrm{p}$ \\
\hline Total score & $1.80(0.38)$ & $2.30(0.39)$ & $1.77(0.39)$ & 8.242 & $<0.001$ & 15.697 & $<0.001$ & $\begin{array}{l}\text { INT vs. EXT } \\
\text { INT vs. COM } \\
\text { EXT vs. COM }\end{array}$ & $\begin{array}{l}-4.954 \\
0.970 \\
5.594\end{array}$ & $\begin{array}{c}<0.001 \\
0.60 \\
<0.001\end{array}$ \\
\hline Dimension sco & & & & & & & & & & \\
\hline Interpersonal & $1.56(0.48)$ & $1.91(0.53)$ & $1.62(0.48)$ & 3.179 & 0.014 & 4.663 & 0.001 & $\begin{array}{l}\text { INT vs. EXT } \\
\text { INT vs. COM } \\
\text { EXT vs. COM }\end{array}$ & $\begin{array}{c}-2.997 \\
-1.475 \\
2.484\end{array}$ & $\begin{array}{l}0.01 \\
0.31 \\
0.04\end{array}$ \\
\hline Affective & $1.62(0.41)$ & $2.09(0.54)$ & $1.63(0.42)$ & 5.217 & $<0.001$ & 10.110 & $<0.001$ & $\begin{array}{l}\text { INT vs. EXT } \\
\text { INT vs. COM } \\
\text { EXT vs. COM }\end{array}$ & $\begin{array}{c}-4.373 \\
-0.346 \\
4.413\end{array}$ & $\begin{array}{c}<0.001 \\
0.94 \\
<0.001\end{array}$ \\
\hline Behavioral & $2.32(0.52)$ & $3.04(0.52)$ & $2.10(0.51)$ & 14.470 & $<0.001$ & 28.714 & $<0.001$ & $\begin{array}{l}\text { INT vs. EXT } \\
\text { INT vs. COM } \\
\text { EXT vs. COM }\end{array}$ & $\begin{array}{l}-4.812 \\
4.096 \\
6.809\end{array}$ & $\begin{array}{l}<0.001 \\
<0.001 \\
<0.001\end{array}$ \\
\hline
\end{tabular}

INT $=$ an internalizing disorder $=$ depressive disorder (F32-33), anxiety disorder (F40-43) and eating disorder (F50); EXT = an externalizing disorder $=$ ADHD (F90.0) and conduct disorder (F91-92); COM= community youth

Fadj $=$ the groups were adjusted for age

$\mathrm{q}=$ Studentized range value 
Table 3. Associations between the Youth psychopathic traits Inventory (YPI) total and dimensional scores* and the ICD-10 based psychiatric disorders among 15- to 17-year-old female out-patients $(\mathrm{n}=163)$. The community girls $(\mathrm{n}=355)$ were used as a reference group. The relationship was analyzed using ORs with $95 \%$ CIs ${ }^{* *}$.

\begin{tabular}{|c|c|c|c|c|c|c|c|c|}
\hline The YPI & $\begin{array}{l}\text { A psychiatric } \\
\text { disorder } \\
(\mathrm{n}=163)\end{array}$ & $\begin{array}{c}\text { A depressive } \\
\text { disorder } \\
(\mathrm{n}=63)\end{array}$ & $\begin{array}{c}\text { An anxiety } \\
\text { disorder } \\
(\mathrm{n}=53)\end{array}$ & $\begin{array}{c}\text { An eating } \\
\text { disorder } \\
(\mathrm{n}=13)\end{array}$ & $\begin{array}{l}\text { ADHD } \\
(n=6)\end{array}$ & $\begin{array}{l}\text { A Conduct } \\
\text { disorder } \\
(\mathrm{n}=13)\end{array}$ & $\begin{array}{l}\text { An internalizing } \\
\text { disorder } \\
(\mathrm{n}=129)\end{array}$ & $\begin{array}{c}\text { An externalizing } \\
\text { disorder } \\
(\mathrm{n}=19)\end{array}$ \\
\hline & $\mathrm{OR}(95 \% \mathrm{CI})$ & $\mathrm{OR}(95 \% \mathrm{CI})$ & $\mathrm{OR}(95 \% \mathrm{CI})$ & OR(95\%CI) & OR(95\%CI) & $\mathrm{OR}(95 \% \mathrm{CI})$ & OR(95\%CI) & $\mathrm{OR}(95 \% \mathrm{CI})$ \\
\hline Total & $1.57(1.05-2.34)$ & $2.01(1.16-3.48)$ & $0.58(0.26-1.28)$ & $0.28(0.04-2.21)$ & $12.91(2.15-77.52)$ & $5.29(1.85-15.12)$ & $1.14(0.72-1.81)$ & $6.84(2.70-17.34)$ \\
\hline \multicolumn{9}{|l|}{ Dimension } \\
\hline Interpersonal & $1.10(0.72-1.67)$ & $1.38(0.77-2.49)$ & $0.69(0.32-1.50)$ & $0.35(0.05-2.69)$ & $3.86(0.83-17.87)$ & $2.42(0.89-6.57)$ & $0.98(0.60-1.58)$ & $2.72(1.16-6.37)$ \\
\hline Affective & $1.25(0.83-1.87)$ & $1.52(0.87-2.64)$ & $0.52(0.22-1.22)$ & -**** & $6.44(2.04-20.32)$ & $3.26(1.30-8.20)$ & $0.93(0.57-1.51)$ & $4.15(1.99-8.65)$ \\
\hline Behavioral & $2.80(1.97-3.98)$ & $3.36(1.98-5.69)$ & $1.50(0.90-2.51)$ & $1.01(0.38-2.73)$ & $18.26(3.45-96.51)$ & $11.19(3.82-32.79)$ & $2.11(1.45-3.08)$ & $12.25(5.09-34.48)$ \\
\hline $\begin{array}{l}{ }^{*} \text { As the minim } \\
{ }^{* *} \text { A risk to ha } \\
{ }^{* * * *} \text { The Analys } \\
\text { The logistic re } \\
\text { A depressive } \\
\text { OR= odds rati } \\
\text { Statistically si }\end{array}$ & $\begin{array}{l}\text { f the YPI mean sc } \\
\text { psychiatric disord } \\
\text { as not applicable d } \\
\text { ion analysis was } \\
\text { der= F32-34; an ar } \\
=\text { confidence inter } \\
\text { cant associations a }\end{array}$ & $\begin{array}{l}\text { res was } 1 \text { and the } \\
\text { as a consequence } \\
\text { to lack of cases } \\
\text { rformed with age- } \\
\text { iety disorder= F4C } \\
\text { al. } \\
\text { presented in bold }\end{array}$ & $\begin{array}{l}\text { maximum } 4 \text {, a Lik } \\
\text { of one point incre } \\
n \text { the upper ( } 2 \text { and } \\
\text { adjusted values. } \\
\text { - } 43 \text {; an eating dis } \\
\text {. }\end{array}$ & $\begin{array}{l}\text { t-type scale was d } \\
\text { e on the Likert-ty } \\
\text { Likert-scale cate } \\
\text { der= F50; ADHD }\end{array}$ & $\begin{array}{l}\text { eloped: } 1 \text { (mean vall } \\
\text { scale. } \\
\text { ries on the Affective } \\
\text { F90.0; a conduct disc }\end{array}$ & $\begin{array}{l}\text { les }<2 \text { ), } 2 \text { (mean valt } \\
\text { dimension of the } Y \\
\text { rder= F91-92. }\end{array}$ & es 2-3), and 3 (me & in values >3). \\
\hline
\end{tabular}

